\title{
PATRONEN IN OMISSIE EN SUBSTITUTIE VAN LIDWOORDEN IN DE TSJECHISCHE VT-VERWERVING VAN HET NEDERLANDS
}

\author{
MARKÉTA KLUKOVÁ
}

\begin{abstract}
Patterns in omission and substitution of articles in Czech foreign language acquisition of Dutch

This paper examines patterns in omission and substitution of articles in Dutch by Czech FL learners. Why do some learners from L1 backgrounds without articles show persistent variability in their article production? Firstly, the paper briefly refers to recent research on L2 and FL language acquisition of articles. Furthermore, article use in Dutch and Czech is described, focusing on definiteness. Finally, a comparative analysis of the determined language tools is carried out in order to compile a hypothesis with regard to the patterns of incorrect article use by Czech FL learners of Dutch. Following Hawkins (2004) and Trenkic (2009), it is argued that the FL learners primarily focus on the semantics of articles instead of taking into account the morpho-syntactic function of this category. This misanalysis potentially leads to omission and substitution errors in the FL article production.
\end{abstract}

Key words: article; acquisition; definiteness; specificity; Dutch; Czech; transfer; omission; substitution

\section{Inleiding}

Uit onderzoek blijkt dat het lidwoordgebruik in de verwerving van een tweede taal (T2) of een vreemde taal (VT) een persistente variabiliteit vertoont op alle beheersingsniveaus (Wethlij 1999; Cornips \& Hulk 2008; Trenkic 2009). Dit fenomeen wordt in nog sterkere mate geobserveerd bij leerders met een moedertaal (T1) zonder lidwoorden (Ionin e.a. 2004, Trenkic 2007, Pimingsdorfer 2010). Een belangrijke vraag is welke patronen er voorkomen in de lidwoordproductie van Tsjechische VT-leerders Nederlands ten opzichte van bepaaldheid. ${ }^{1}$

Teneinde de patronen in omissie en substitutie van lidwoorden in de Tsjechische VT-verwerving van het Nederlands te kunnen onderzoeken, wordt in deze bijdrage eerst

1 Het foutieve lidwoordgebruik gekoppeld aan het genus en de telbaarheid wordt in deze bijdrage buiten beschouwing gelaten. 
een beknopt overzicht gepresenteerd van recent onderzoek naar T2- en VT-verwerving van lidwoorden. In de tweede plaats wordt de markering van (on)bepaaldheid in kaart gebracht in zowel het Nederlands als het Tsjechisch. Ten slotte wordt er gekeken naar voornoemde patronen in omissie en substitutie en worden er enkele hypotheses geformuleerd met betrekking tot de Tsjechische leerders van het Nederlands als vreemde taal.

\section{Onderzoek naar T2- en VT-verwerving van lidwoordgebruik}

De verwerving van lidwoordgebruik trekt de aandacht van toegepaste taalwetenschappers, aangezien het een complex taalfenomeen betreft dat vaak een struikelblok vormt bij zowel T2- en VT-leerders, als T1-sprekers (Wethlij 1999; Sharma 2005; Rozendaal \& Baker 2006, 2008; Trenkic 2008).

De fundamentele dichotomie van het mentalistische en behavioristische onderzoek naar T2- en VT-verwerving wordt weerspiegeld in de studies naar de verwerving van lidwoordgebruik. Onder de mentalistische theorieën die op het generativisme berusten, valt de Fluctuation Hypothesis van Ionin (2003, 2004). Haar hypothese stelt dat:

"[...] errors in L2-data stem from the learners fluctuating between two or more parameter settings, some of which are not appropriate for the target language." (Ionin et al. 2004: 20)

Ionin gaat ervan uit dat er tijdens het T2-lidwoordgebruik een beroep wordt gedaan op de Universal Grammar (UG) van Chomsky. Lidwoorden worden ingedeeld op basis van de zogenaamde Article Choice Parameter. Deze parameter wordt volgens Ionin door T2-leerders toegepast om een correct lidwoordonderscheid te kunnen maken tijdens de fluctuatie tussen bepaaldheid en specificiteit. Ionin, Zubizarreta \& Maldonado (2008) deden tevens onderzoek naar het lidwoordgebruik in het Engels door Russische leerders. Zij concludeerden dat Russische T2-leerders directe toegang hebben tot de semantische universalia van de UG waardoor specificiteit invloed uitoefent op hun lidwoordgebruik. Bovendien werd geconstateerd dat het T2-lidwoordgebruik afhangt van de taalvaardigheid. Hoe hoger het taalvaardigheidsniveau, hoe minder foutief het lidwoordgebruik blijkt te zijn.

De behavioristische benadering daarentegen neemt de rol van T1-gewoontes als uitgangspunt. De T2- en VT-verwerving wordt positief of negatief beïnvloed door de reeds verworven T1-structuren. Deze interactie wordt transfer genoemd, waarbij negatieve transfer (interferentie) zich uit in de vorm van een fout in de te leren taal. In recent onderzoek wordt steeds vaker uitgegaan van transfer (Trenkic 2007, Hiligsmann e.a. 2008, Pimingsdorfer 2010). Tot de taalwetenschappers die voor transfer pleiten, behoort ook Trenkic (2002, 2007, 2008, 2009). Zij veronderstelt dat de moeilijkheden in het lidwoordgebruik waarmee T2-leerders met een T1 zonder lidwoorden geconfronteerd worden, worden veroorzaakt door de primaire morfosyntactische functie van lidwoorden (cf. Hawkins 2004). T2-leerders met een T1 zonder lidwoorden maken namelijk gebruik van andere taalmiddelen om (on)bepaaldheid en (niet-)specificiteit uit te drukken. Trenkic (2009: 123) argumenteert tevens dat T2-leerders niet in staat zijn om syntactische determinatoren te herkennen, aangezien zij hoofdzakelijk op de semantiek van lidwoorden focussen: 
"Their [determiners'] primary function is to express of certain meanings, not to grammatically signal that a noun is coming, and in that particular sense languages without articles can be said not to have the syntactic category determiner."

Als gevolg daarvan worden conform de Syntactic Misanalysis Account van Trenkic (2007, 2009) lidwoorden incorrect geanalyseerd als procedural adjectives.

Pimingsdorfer (2010) onderzocht het lidwoordgebruik in het Duits van Tsjechische leerders en concludeerde dat de meest voorkomende fouten omissiefouten waren wat:

“[...] hauptsächlich mit unterschiedlichen Vermeidungsstrategien (auch mit versuchter Vermeidung von Kasus- und insb. Genus-Fehlern) sowie mit auf die komplexe Divergenz zwischen L1 und L2 zurückzuführenden Interferenzproblemen (negativer interlingualer Transfer) erklärt werden kann.” (Pimingsdorfer 2010: 147)

De studie van Kluková (2016) is eveneens op transfer gebaseerd. Met het oog op de interferentie werd een kleinschalige foutenanalyse uitgevoerd van schriftelijke taaluitingen van Tsjechische eerstejaars studenten Nederlands. ${ }^{2}$ De meest voorkomende fout bleek de eliminatie van een lidwoord te zijn. De omissiefouten maakten $70,7 \%$ uit van alle vastgestelde fouten (zie Figuur 1).

Figuur 1: Verdeling van fouten

\begin{tabular}{|c|c|c|c|c|c|}
\hline & omissiefouten & $\begin{array}{c}\text { bepaaldheid en } \\
\text { specificiteit }\end{array}$ & genusonderscheid & andere fouten $^{1}$ & totaal \\
\hline aantal NP's & 58 & 9 & 8 & 7 & 82 \\
\hline$\%$ & $70,7 \%$ & $10,9 \%$ & $9,8 \%$ & $8,6 \%$ & $100 \%$ \\
\hline
\end{tabular}

Verder werd vastgesteld dat lidwoorden voornamelijk werden weggelaten in de [-bepaald] conditie, namelijk in 79,3\% van alle omissiefouten (Kluková 2016). Zie (1) en (2).

(1) Het is [een] goed idee.

(2) Ik wil bij je logeren, je hebt [een] groot huis.

\section{Bepaaldheid}

Om een verhaal coherent te houden moeten er systematische verwijzingen naar referenten worden gemaakt met behulp van verschillende taalmiddelen. De manier waarop een spreker verwijst, hangt af van het type informatie dat hij wil meedelen en van de mate waarin de spreker en de hoorder het kennisgeheel in het discours delen (Rozendaal \& Baker 2006). De 'nominale (on)bepaaldheid' betreft de identificeerbaarheid van de referent voor de hoorder. De referent is bepaald indien de spreker de referent als uniek

2 De foutenanalyse was gebaseerd op een corpus van 20 schriftelijke taken. Gezien het beperkte corpus kunnen de resultaten niet als statistisch significant worden beschouwd. 
en identificeerbaar beschouwt voor de hoorder. Bij introductie van een nieuwe referent is er sprake van een onbepaalde referent. De categorie '(niet-)specificiteit' indiceert of de referent identificeerbaar is voor de spreker zelf (Hengeveld \& Mackenzie 2008).

Bepaaldheid kan volgens Krámský (1972) op drie manieren tot uitdrukking komen: ten eerste door syntactisch onafhankelijke woorden, zoals de lidwoorden in het Nederlands, ten tweede door affixen die met de nominale constituent (NP) zijn verbonden, zoals in het Bulgaars, en ten slotte door de (syntactische) context van de NP, zoals in het Tsjechisch.

\subsection{Bepaaldheid in het Nederlands}

Zoals reeds vermeld, wordt bepaaldheid in het Nederlands geuit door middel van het lidwoordgebruik. Lidwoorden behoren binnen de NP tot de categorie 'determinatoren'

Determinatoren worden ook identificerende bepalingen genoemd, aangezien ze de relatie aangeven tussen de kern van de nominale constituent en de referent. Zoals numeralia en pronomina komen lidwoorden niet predicatief voor en kunnen ze niet asyndetisch worden gebruikt met andere determinatoren (Van de Velde 2009: 40).

De distributie van de Nederlandse lidwoorden is afhankelijk van het genus, het getal, de telbaarheid, de bepaaldheid en de specificiteit van het nomen. De bepaalde lidwoorden de en het leiden een bepaalde NP in, terwijl het onbepaalde lidwoord een en het nul-lidwoord (Ø) een onbepaalde constituent introduceren. Zie (3) en (4). ${ }^{3}$

(3) Zag je de man die daar liep?

(4) Ik heb een interessant boek gelezen.

Naast de (on)bepaaldheid speelt verder ook (niet-)specificiteit een rol in het lidwoordgebruik in het Nederlands. Deze categorie verwijst zoals gezegd naar de identificeerbaarheid van de referent voor de spreker. In (4) is de referent [-bepaald], maar wel identificeerbaar voor de spreker, dus [+specifiek]. Aantonen dat (on)bepaaldheid specifiek of niet-specifiek is, kan los van de context zeer lastig zijn. In de vakliteratuur worden daarom de grammaticale en semantische/pragmatische specificiteit onderscheiden (Lyons 1999, Hengeveld \& Mackenzie 2008, Trenkic 2009). Vanuit een grammaticaal oogpunt (los van de context) zijn de NP's in (5) en (6) onbepaald en niet-specifiek, maar uit de context blijkt vervolgens dat de identificeerbaarheid van de referent voor de spreker verschilt. Zie (5) en (6).

(5) Ik ga morgen een trui kopen. Het maakt me niet uit welke kleur zij zal hebben. [-bepaald] [-specifiek]

(6) Ik ga morgen een trui kopen. Het maakt me niet uit dat die te duur is.

[-bepaald] [+specifiek]

Zie figuur 2 voor een samenvatting.

3 Naast de bepaalde en onbepaalde NP's introduceren de Nederlandse lidwoorden ook categoriale en generieke NP's. Deze twee soorten blijven in deze bijdrage echter buiten beschouwing. 
Figuur 2: Indeling van de Nederlandse lidwoorden op basis van bepaaldheid

\begin{tabular}{|c|c|c|c|c|}
\hline & \multicolumn{2}{|c|}{ enkelvoud } & \multicolumn{2}{|c|}{ meervoud } \\
\hline & [+bepaald] & [-bepaald] & [+bepaald] & [-bepaald] \\
\hline [+specifiek] & \multirow{2}{*}{ de / het } & \multirow{2}{*}{ een } & \multirow{2}{*}{ de } & \multirow{2}{*}{$\varnothing$} \\
\hline [-specifiek] & & & & \\
\hline
\end{tabular}

\subsection{Bepaaldheid in het Tsjechisch}

De Tsjechische taal is een sterk flecterende taal die, even als de meeste Slavische talen, geen lidwoorden bezit (cf. Comrie \& Corbett 2002). Dankzij een rijk casussysteem zijn de zinsdelen goed identificeerbaar waardoor de woordvolgorde in het Tsjechisch nogal vrij is (Hlavsa 1972, Daneš e.a. 1987, Grepl e.a. 1995). Hoewel de verbuiging van de nomina niet de enige structurele oorzaak is van de afwezigheid van lidwoorden, is er typologisch wel sprake van contingentie tussen lidwoorden en het casusparadigma. Terwijl de Slavische talen meestal beschikken over een casussysteem met gemiddeld zeven naamvallen, zijn het Bulgaars en het Macedonisch nominaal verarmd (alleen nominatief en accusatief). Deze twee talen zijn ook de enige Slavische standaardtalen die een bepaald lidwoord gebruiken (Trenkic 2009). ${ }^{4}$

In het Tsjechisch vloeien de categorieën (on)bepaaldheid en (niet-)specificiteit voort uit de context. Door de vrijere woordvolgorde kan de (on)bepaaldheid in het Tsjechisch worden geuit op basis van van het thema-rhema-principe (Daneš e.a. 1987) dat kan worden vergeleken met het Nederlandse links-rechts-principe (Haeseryn e.a. 1997). Dit principe houdt in dat de informatieve waarde van de zinsdelen stijgt van links naar rechts. Hierdoor wordt het thema meestal als bepaald beschouwd en het rhema, waarin nieuwe informatie wordt geïntroduceerd, vaak als onbepaald. Prototypische voorbeelden illustreren dat de referentiële relaties in het Tsjechisch worden uitgedrukt door middel van volgorde (Karlík e.a. 2002). Zie (7) en (8). ${ }^{5}$

(7) Chlapec odnesl dřevo do kůlny. De jongen bracht hout naar de schuur.

(8) Do kůlny odnesl dřevo chlapec. Naar de schuur werd hout gebracht door de/een jongen.

Het subject in (7) is thematisch en de referentie kan alleen bepaald en specifiek zijn, terwijl de NP chlapec in (8) rhematisch is en de referentie zowel bepaald ('de jongen') als onbepaald ('een jongen') kan zijn, afhankelijk van de context (Karlík e.a. 2002).

Om de identificeerbaarheid van de referent te benadrukken kan de Tsjechische spreker facultatief gebruik maken van demonstratieve of onbepaalde pronomina. Voor de markering van bepaaldheid kunnen de demonstratieve pronomina ten en tento worden

4 In het Bulgaars en het Macedonisch worden bepaalde lidwoorden gepostponeerd als suffix bij het eerste woord van de NP. Naast deze twee talen kan bepaaldheid met behulp van lidwoorden ook gemarkeerd worden in sommige Noord-Russische dialecten (Weiss 2010).

5 De woordvolgorde kan ook in het Nederlands een rol spelen met betrekking tot het onderscheiden van bepaaldheid en specificiteit. Vergelijk de volgende voorbeelden met het oog op de positie van het subject: er belt elke dag een jongen aan [-bepaald] [-specifiek] en er belt een jongen elke dag aan [-bepaald] [+specifiek]. 
gebruikt, zie (9), en voor de markering van onbepaaldheid het onbepaalde pronomen nějaký en het numerale jeden, zie (10). ${ }^{6}$

(9) Našla jsi ten článek?

Heb je het artikel gevonden?

(10) Staví se tam nějaké nové domy. Er worden $\varnothing$ nieuwe huizen gebouwd.

Hoewel het Tsjechisch geen lidwoorden kent, bestaat er een tendens tot grammaticalisering van enkele taalelementen die lidwoordfuncties lijken te bekleden (Mathesius 1926, Dobiáš 2006, Konvička 2017). Dobiáš (2006) signaleert in de spreektaal een overmatig gebruik van het demonstratieve pronomen ten, het onbepaalde pronomen nějaký en het numerale jeden die in de functie van bepaalde en onbepaalde lidwoorden optreden. Deze taalmiddelen worden in deze functies onbeklemtoond uitgesproken. Er wordt echter benadrukt dat dit fenomeen voorlopig uitsluitend in de spreektaal waar te nemen is. Deze taalelementen zouden in de schrijftaal als redundant worden beschouwd.

\section{Patronen in omissie en substitutie van lidwoorden}

In de vakliteratuur zijn er meerdere studies die laten zien dat T2- en VT-leerders met een T1 zonder lidwoorden, vaak lidwoorden weglaten en substitueren conform bepaalde systematische patronen. Een van die patronen is bijvoorbeeld dat er meer omissiefouten in een NP gemodificeerd door een adjectief voorkomen dan in een simpele niet-gemodificeerde constituent (Trenkic 2002, 2007, Sharma 2005). Verder worden lidwoorden frequenter weggelaten voor nomina in thema-posities dan in rhema-posities en tevens als T2- en VT-leerders naar een meer saillante referent verwijzen (Trenkic 2009). Er worden ten slotte meer substitutiefouten gemaakt in de [+bepaald] [-specifiek] en [-bepaald] [+specifiek] condities, aangezien de T2- en VT-leerders worden beïnvloed door specificiteit (Ionin et al. 2004). ${ }^{7}$

\subsection{Patronen in omissie en substitutie in het Nederlands}

Op basis van het eerder beschreven theoretisch kader kunnen we aannemen dat T1 een aanzienlijke rol speelt in de VT-verwerving van lidwoorden. Aangezien we de lidwoordproductie van Tsjechische leerders Nederlands onder de loep nemen, is er sprake van het lidwoordsysteem van een Germaanse taal dat verworven wordt door leerders met een Slavische T1 zonder lidwoorden. Rekening houdend met de sterk uiteenlopende

6 De beschreven taalmiddelen om (on)bepaaldheid uit te drukken worden in het Tsjechisch geflecteerd. De vorm van de pronomina en de numeralia hangt af van het genus en het getal van de kern van de $\mathrm{NP}$, bijvoorbeeld ten muž (de man), ta žena (de vrouw), to ditě (het kind), ti lidé (de mensen); nějakýl jeden muž (een man), nějaká/jedna žena (een vrouw), nějaké/jedno dítě (een kind), nějací lidé (Ø mensen).

7 Ionin e.a. (2004) onderscheiden vier verschillende combinaties van bepaaldheid en specificiteit in het Engels, namelijk [+bepaald][+specifiek], [+bepaald][-specifiek], [-bepaald][+specifiek] en [-bepaald] [-specifiek]. Beweren dat bepaaldheid ook niet-specifiek kan zijn, lijkt echter (los van de context) aanvechtbaar, aangezien het bepaalde lidwoord altijd verwijst naar een specifieke entiteit of categorie (cf. Broekhuis \& Den Dikken 2012). 
markering van (on)bepaaldheid in het Nederlands en het Tsjechisch kunnen we in de lidwoordproductie omissie- en substitutiefouten verwachten die worden beïnvloed door negatieve transfer. Terwijl de bepaaldheid in het Nederlands met behulp van lidwoorden wordt gemarkeerd, komt de bepaaldheid in het Tsjechisch, zoals gezegd, tot uitdrukking door middel van de volgorde en een facultatief gebruik van demonstratieve en onbepaalde pronomina of numeralia.

Ons baserend op Trenkic $(2002,2007,2009)$ en Hawkins (2004) veronderstellen we dat de meeste omissie- en substitutiefouten in het lidwoordgebruik van VT-leerders met een T1 die geen lidwoorden onderscheidt, kunnen worden veroorzaakt door de elementaire morfosyntactische functie van lidwoorden die door de VT-leerders wordt gemisinterpreteerd. De VT-leerders focussen vermoedelijk primair op de semantiek van lidwoorden in plaats van de structurele en procedurele functie van lidwoorden in aanmerking te nemen. Gezien het feit dat de (on)bepaaldheid in het Tsjechisch duidelijk is uit het discours, bestaat er een gebrek aan syntactische determinatoren om deze categorie te markeren. De VT-leerders zien de lidwoorden als pragmatisch overbodig, omdat ze veronderstellen dat de referent al wel identificeerbaar is voor de hoorder. De focus van de VT-leerders op de betekenis van lidwoorden zorgt daarom voor verwarring. Hoe semantisch transparanter het te leren grammaticale verschijnsel namelijk is, hoe gemakkelijker het blijkt te zijn om het onder de knie te krijgen (cf. Trenkic 2009, Pimingsdorfer 2010).

Verder kan worden vermoed dat de meeste omissiefouten (op een lager taalbeheersingsniveau) worden gemaakt in de [-bepaald] conditie (cf. Pimingsdorfer 2010, Kluková 2016). Omissiefouten kunnen worden veroorzaakt door de T1-gewoonte van de Tsjechische VT-leerders geen syntactische taalmiddelen te gebruiken om een nieuwe NP in te leiden. Zie (11).

(11) Mijn zus heeft een huis gebouwd.

Má sestra postavila dům.

Ten slotte kunnen de VT-leerders veel substitutiefouten maken in de [+bepaald][-specifiek] en [-bepaald] [+specifiek] condities. Dezer ontstaan mogelijk doordat specificiteit op grond van een pragmatische interpretatie voortvloeit uit de context. Zie (12) en (13).

(12) Ik wil de eigenaar van deze auto zien. Het maakt niet uit wie dat is.

Chci vidět majitele tohoto auta. Je jedno, kdo to je.

(13) Mijn man heeft gisteren een vriendin bezocht. Zij heet Petra en is heel lief. Můj muž včera navštívil jednu př́ítelkyni. Jmenuje se Petra a je velmi milá. ${ }^{8}$

8 Interessant is dat het gebruik van het numerale jeden in het Tsjechische voorbeeld verplicht is om aan te geven dat de spreker de referent wel identificeert. Het gebruik van het onbepaalde pronomen nějakou zou namelijk markeren dat de referent niet identificeerbaar is voor de spreker. 


\section{Conclusie}

Uitgaande van recent onderzoek naar de T2- en VT-verwerving van lidwoordgebruik en de geschetste taalmiddelen om (on)bepaaldheid te uiten in zowel het Nederlands als het Tsjechisch wordt in deze bijdrage een hypothese geformuleerd met betrekking tot de patronen in omissie- en substitutiefouten in het lidwoordgebruik door Tsjechische VT-leerders Nederlands.

De hypothese stelt dat de lidwoordverwerving van Tsjechische VT-leerders Nederlands wordt beïnvloed door negatieve transfer van de reeds aangeleerde T1-structuren. De manier waarop de categorie (on)bepaaldheid in beide talen wordt gemarkeerd, wijkt namelijk sterk af. Terwijl in het Nederlands lidwoorden worden ingedeeld op basis van bepaaldheid, wordt in het Tsjechisch vooral het thema-rhema-principe toegepast. Het gebruik van andere taalmiddelen om (on)bepaaldheid te markeren en het gebrek aan puur syntactische determinatoren draagt ertoe bij dat de Tsjechische leerders zich primair op de semantiek van lidwoorden richten in plaats van op de morfosyntactische functie van dit grammaticale verschijnsel. Verder formuleren we het vermoeden dat Tsjechische VT-leerders meer omissiefouten maken in de [-bepaald] conditie. Dat kan worden verklaard door de tendens van de leerders om lidwoorden als redundant te beschouwen als zij een nieuwe NP introduceren. In verband met substitutiefouten kan de invloed van specificiteit worden verwacht in de context waarin bepaaldheid en specificiteit fluctueren.

In verder onderzoek zal de hypothese worden getoetst door middel van een foutenanalyse. Tevens kan aandacht worden besteed aan de verwerving van het verband tussen de vorm en de betekenis van lidwoorden en eventuele didactische implicaties.

\section{BIBLIOGRAFIE}

BROEKHUIS, HANS \& MARCEL DEN DIKKEN (2012). Syntax of Dutch. Nouns and Nouns Phrases Volume 2. Amsterdam: Amsterdam University Press.

COMRIE, BERNARD \& GREVILLE CORBETT (2002). The Slavonic Languages. London/New York: Routledge.

CORNIPS, LEA \& AAFKE HULK (2008). "Factors of success and failure in the acquisition of grammatical gender in Dutch", in: Second Language Research 24, 3, 267-296.

DANEŠ, FRANTIŠEK (1987). Mluvnice češtiny. Praha: Academia.

DOBIÁŠ, DANIEL (2006). Posuny ve vyjadřrování kategorie určenosti v současné spisovné a nespisovné češtině. Masterscriptie. Praha: Univerzita Karlova.

GREPL, MIROSLAV (1995). Př́ruční mluvnice češtiny. Praha: Nakladatelství Lidové noviny.

HAESERYN, WALTER e.a. (1997). Algemene Nederlandse spraakkunst. Groningen/Deurne: Martinus Nijhoff/Wolters Plantyn.

HAWKINS, JOHN (2004). Efficiency and complexity in grammars. Oxford: Oxford University Press.

HENGEVELD, KEES. \& JOHN MACKENZIE (2008). Functional Discourse Grammar. A typologically-based theory of language structure. Oxford: Oxford University Press.

HILIGSMANN, PHILIPPE e.a. (2008). "Praktijkgerelateerd contrastief onderzoek naar vreemde-taalverwerving", in: Toegepaste Taalwetenschap in Artikelen 80, 19-28.

HLAVSA, ZDENĚK (1972). "K protikladu určenosti v češtině”, in: Slovo a slovesnost 33, 3, 199-203.

IONIN, TANIA (2003). Article semantics in L2 acquisition. Massachusetts: MIT working papers in linguistics. 
IONIN, TANIA e.a. (2004). "Article semantics in L2 acquisition: the role of specificity", in: Language Acquisition 1, 2, 3-69.

IONIN, TANIA e.a (2009). "Acquisition of article semantics by child and adult L2-English learners", in: Bilingualism: Language and Cognition 12, 3, 337-361.

KARLÍK, PETR e.a. (2002). Encyklopedický slovník češtiny. Praha: Nakladatelství Lidové noviny.

KLUKOVÁ, MARKÉTA (2016). "Lidwoorden op z’n Tsjechisch: Problematisch lidwoordgebruik van volwassen Tsjechische leerders Nederlands", in: Roczniki Humanistyczne 64, 5, 47-62.

KONVIČKA, MARTIN (2017). De opkomst van de Nederlandse grammatica. Olomouc: Univerzita Palackého v Olomouci, 122-127.

KRÁMSKÝ, JIŘÍ (1972). The article and the concept of definiteness. Den Haag: Mouton.

LYONS, CHRISTOPHER (1999). Definiteness. Cambridge: Cambridge University Press.

MATHESIUS, VILÉM (1926). "Přívlastkové ten, ta, to v hovorové češtině", in: Naše ř reč 10, 2, 39-41.

PIMINGSDORFER, THOMAS (2010). Untersuchungen zur Didaktik des Gebrauchs von definitem, indefinitem sowie Null-Artikel im Deutschen für Lernende und Lehrende mit artikellosen Erstsprachen. Wien: Univesität Wien.

ROZENDAAL, MARGOT \& ANNE BAKER (2006). “'Oeh, dat is een koekje’: De verwerving van de referentiële functies van lidwoorden en pronomina”, in: Toegepaste taalwetenschap in artikelen 75, 1, 29-39.

ROZENDAAL, MARGOT \& ANNE BAKER (2008). "A cross-linguistic investigation of the acquisition the pragmatics of indefinite and definite reference in two-year-olds", in: Journal of Child Language $35,773-807$.

SHARMA, DEVYANI (2005). "Language transfer and discourse universals in Indian English article use", In: Studies in Second Language Acquisition 27, 535-566.

TRENKIC, DANIJELA (2002). "Form-meaning connections in the acquisition of English articles", in: S. Foster-Cohen e.a. (red.), EUROSLA Yearbook, vol. 2, Amsterdam: John Benjamins, 115-133.

TRENKIC, DANIJELA (2007). "Variability in L2 article production: Beyond the representational deficit vs. Processing constraints debate", in: Second Language Research 23, 3, 189-327.

TRENKIC, DANIJELA (2008). "The representation of English articles in second language grammars: Determiners or adjectives?", in: Bilingualism: Language and Cognition 11, 1, 1-18.

TRENKIC, DANIJELA (2009). "Accounting for patterns of article omissions and substitutions in second language production”, in: Maria Pilar García del Mayo e.a. (red.). Second language acquisition of articles: empirical findings and theoretical implications. Amsterdam/Philadelphia: John Benjamins, $115-143$.

UNGERMANNOVÁ, EVA (2015). De verwerving van het lidwoord door Tsjechische leerders van het Nederlands als vreemde taal. Praha: Univerzita Karlova.

VAN DE VELDE, FREEK (2009). De nominale constituent. Structuur en geschiedenis. Leuven: Universitaire Pers.

WEISS, DANIEL (2010). “Osteuropa als eurolinguistisches Areal”, in: Uwe Hinrichs (red.): Handbuch der Eurolinguistik. Wiesbaden: Harrassowitz, 435-457.

WETHLIJ, ALEX (1999). "Het lidwoord: een onderschatte categorie in het onderwijs van het Nederlands aan anderstaligen”, in: Siegfried Theissen \& Philippe Hiligsmann (red.): Morfologiedagen 1997: handelingen van het colloquium aan de Université de Liège op 23 en 24 september 1997. Liège: Université de Liège, 71-86.

\section{TENDENCE PŘI OMISI A SUBSTITUCI ČLENŮ V ČESKÉ AKVIZICI NIZOZEMŠTINY JAKO CIZÍHO JAZYKA}

Tento článek zkoumá tendence při omisi a substituci členů v nizozemštině českými studenty nizozemského jazyka. Z jakého důvodu vykazují někteří studenti s mateřským jazykem bez členů trvalou variabilitu $v$ použití členů $v$ cizím jazyce? Příspěvek nejdříve stručně odkazuje na současný výzkum akvizice druhého a cizího jazyka. Dále popisuje použití členů v nizozemštině a češtině z hlediska určitosti. 
Nakonec je provedena kontrastivní analýza jazykových prostředků určitosti za účelem sestavení hypotézy týkající se tendencí nesprávného použití členů českými studenty nizozemštiny jako cizího jazyka. S odkazem na Hawkinse (2004) a Trenkicovou (2009) lze předpokládat, že se studenti jazyka primárně soustředí na sémantiku členů místo zohlednění morfosyntaktické funkce dané gramatické kategorie.

Tato nesprávná analýza vede potenciálně k chybné omisi či substituci v produkci členů v cizím jazyce.

\author{
Markéta Kluková \\ Univerzita Palackého \\ E-mail: marketa.klukova@gmail.com
}

